\title{
IFITM5 pathogenic variant causes osteogenesis imperfecta $V$ with various phenotype severity in Ukrainian and Vietnamese patients
}

Lidiia Zhytnik ${ }^{1 *}$ (D, Katre Maasalu ${ }^{1,2}$, Binh Ho Duy ${ }^{3}$, Andrey Pashenko $^{4}$, Sergey Khmyzov ${ }^{4}$, Ene Reimann ${ }^{5,6}$, Ele Prans $^{6}$, Sulev Kõks ${ }^{7}$ and Aare Märtson ${ }^{1,2}$

\begin{abstract}
Background: Osteogenesis imperfecta $(\mathrm{OI})$ covers a spectrum of bone fragility disorders. Ol is classified into five types; however, the genetic causes of OI might hide in pathogenic variants of 20 different genes. Often clinical OI types mimic each other. This sometimes makes it impossible to identify the Ol type clinically, which can be a risk for patients. Up to $90 \%$ of OI types I-IV are caused by pathogenic variants in the COL $1 A 1 / 2$ genes. Ol type $V$ is caused by the c.-14C > T pathogenic variant in the 5'UTR of the IFITM5 gene and is characterized by hyperplastic callus formation and the ossification of interosseous membranes.

Results: In the current study, we performed IFITM5 5'UTR region mutational analysis using Sanger sequencing on 90 patients who were negative for COL1A1/2 pathogenic variants. We also investigated the phenotypes of five patients with genetically confirmed OI type $\mathrm{V}$. The proportion of Ol type $\mathrm{V}$ patients in our cohort of all Ol patients was $1.48 \%$. In one family, there was a history of $\mathrm{Ol}$ in at least three generations. Phenotype severity differed from mild to extremely severe among patients, but all patients harbored the same typical pathogenic variant. One patient had no visible symptoms of OI type $\mathrm{V}$ and was suspected to have had OI type IV previously. We also identified a case of extremely severe hyperplastic callus in a 15-year-old male, who has hearing loss and brittleness of teeth.

Conclusions: OI type $V$ is underlined with some unique clinical features; however, not all patients develop them. The phenotype spectrum might be even broader than previously suspected, including typical Ol features: teeth brittleness, bluish sclera, hearing loss, long bones deformities, and joint laxity. We suggest that all patients negative for COL1A1/2 pathogenic variants be tested for the presence of an IFITM5 pathogenic variant, even if they are not expressing typical $\mathrm{Ol}$ type $\mathrm{V}$ symptoms. Further studies on the pathological nature and hyperplastic callus formation mechanisms of $\mathrm{Ol}$ type $\mathrm{V}$ are necessary.
\end{abstract}

Keywords: Osteogenesis imperfecta, IFITM5, Type V, Hyperplastic callus, Bone fragility

\footnotetext{
*Correspondence: Lidiia.Zhytnik@ut.ee; Lidiia.zhytnik@ut.ee

'Department of Traumatology and Orthopeadics, University of Tartu,

Puusepa 8, 51014 Tartu, Estonia

Full list of author information is available at the end of the article
}

(c) The Author(s). 2019 Open Access This article is distributed under the terms of the Creative Commons Attribution 4.0 International License (http://creativecommons.org/licenses/by/4.0/), which permits unrestricted use, distribution, and reproduction in any medium, provided you give appropriate credit to the original author(s) and the source, provide a link to the Creative Commons license, and indicate if changes were made. The Creative Commons Public Domain Dedication waiver (http://creativecommons.org/publicdomain/zero/1.0/) applies to the data made available in this article, unless otherwise stated. 


\section{Background}

Osteogenesis imperfecta (OI) covers a spectrum of rare, genetic connective tissue disorders, outlined by bone fragility, skeletal deformations, and recurrent fractures [1]. Typical symptoms of OI include blue sclera, dentinogenesis imperfecta (DI), hearing loss, and joint laxity [2-4].

The genetic spectrum of OI is composed of 20 different OI genes [5-7]. Up to $90 \%$ of OI cases arise from the heterozygous pathogenic variants of the COL1A1 (OMIM 120150) and COL1A2 (OMIM 120160) genes, which code for collagen type I $\alpha 1,2$ chains [8]. One more gene representing autosomal dominant OI is the IFITM5 (OMIM 610967) gene, which codes for a bone-restricted ifitm-like protein (BRIL) [9]. Up to 5\% of individuals from OI population harbor pathogenic variants in the IFITM5 gene [10]. The remaining OI cases are caused by pathogenic variants in the recessive OI genes [7, 11-23].

Genetic heterogeneity is reflected in the broad variability of OI phenotypes. In 1979, David Sillence classified OI based on the clinical severity as follows: type I-nondeforming OI with blue sclera; type II-lethal OI; type III-severe deforming OI; and type IV-variable OI without blue sclera [4]. In 2000, based on histological and radiological evidences, Glorieux et al. proposed the existence of an additional variant, OI type V [24]. This particular OI type differed due to its mesh-like pattern of lamellation, hyperplastic callus (HPC) formation, and calcification of the interosseous membrane in the forearm [24-26]. Patients with OI type V are described to mimic symptoms of OI type IV with moderate severity of long-bone deformities, vertebral compression fractures, scoliosis, and the same number of fractures. However, unlike type IV, patients with OI type $\mathrm{V}$ were claimed not to develop DI or blue sclera [25].

Recent studies have introduced variability in the OI type $\mathrm{V}$ phenotypes [25, 27-30]. The spectrum of OI type $\mathrm{V}$ phenotypes has been expanded with phenotypes mimicking OI type I and III and [31]. Despite phenotype variations, all patients with OI type $\mathrm{V}$ harbor the same genetic change - a pathogenic variant in the $5^{\prime}$ untranslated (UTR) region of the IFITM5 gene, c. $-14 \mathrm{C}>\mathrm{T}[32$, 33].

Neither the physiological function of the IFITM5 gene product, BRIL protein, nor the effect of the mutated protein is fully understood. As it is known, c. $-14 \mathrm{C}>\mathrm{T}$ substitution in the 5'UTR region of the IFITM5 gene creates a new upstream start codon and causes the inclusion of five additional amino acids to the N-termini of the BRIL protein (MALEP) [34]. However, the exact pathological mechanism of OI type V remains unclear; it was hypothesized that the MALEP-IFITM5 acts in a neomorphic manner, gaining a new molecular function [35].

Despite the genetic cause of OI type $\mathrm{V}$ first being published in 2012, the discovery of patients harboring the
c.-14C > T IFITM5 variant is still rare, and many of them do not develop traits characteristic of OI type $\mathrm{V}$ [31-33]. Thus, the description of phenotypes in patients of OI type $\mathrm{V}$ is of particular interest, as it enriches our understanding of phenotypical variability and approaches to the diagnosis of OI type $\mathrm{V}$.

In this study, we have screened for the presence of a c. $-14 C>$ T IFITM5 pathogenic variant in a cohort of 90 unrelated Estonian, Ukrainian, and Vietnamese OI patients negative for collagen type I pathogenic variants with diverse OI phenotypes. Herein, we report the phenotypical characteristics captured during the screening of five OI type $\mathrm{V}$ patients with identical c.-14C $>\mathrm{T}$ pathogenic variants in the IFITM5 gene and phenotypes of different severity. Also, for the first time, we report a case of an OI type $\mathrm{V}$ patient with extremely severe callus and hearing loss.

The management and diagnosis of OI is performed by clinical geneticists. OI type $\mathrm{V}$ is one of the rarest $\mathrm{OI}$ types, as such, is often misdiagnosed. We believe that sharing the data from patients with rare OI types is an important contribution to the field. In many countries, not all patients undergo genetic testing and $\mathrm{OI}$ is often diagnosed based on phenotypical features. This article illustrates the high degree of variation in the clinical symptoms of OI type V. Additionally, it highlights the critical importance of identifying the specific variant at hand to develop an appropriate treatment strategy and counseling for family planning.

\section{Materials and methods}

The study was performed using patients from the OI biobank of the Clinic of Traumatology and Orthopedics from the University of Tartu, Estonia (UT OI biobank). The UT OI biobank consists of 237 OI families from Estonia, Ukraine, and Vietnam, including 337 samples from OI affected individuals and their healthy relatives. Informed written consent was collected from all subjects and controls, or their legal representatives, prior to their participation in the study. The study was conducted in accordance with the Helsinki Declaration and authorized by the Ethical Review Committee on Human Research of the University of Tartu (Permit no. 221/M-34), the Ethical Review Board of Hue University Hospital (approval No. 75/CNBVYD), and the Sytenko Institute of Spine and Joint Pathology of the Ukrainian Academy of Medical Sciences. Details of the patient recruitment process are described elsewhere. [36-38]

For the current study, we used a cohort of 90 unrelated OI patients negative for $C O L 1 A 1 / 2$ pathogenic variants. Patients were previously diagnosed with OI of different severity (Sillence classification, types I-IV) based on clinical features. Only one patient was suspected to have OI type $\mathrm{V}$ due to significant, visible HPC. 
To capture a typical pathogenic variant causing OI type $\mathrm{V}$, a cohort of selected patients were screened for the presence of a c. $-14 \mathrm{C}>\mathrm{T}$ pathogenic variant in the IFITM5 gene. Focusing on the mutational analysis of the specific locus, we have selected Sanger sequencing of the 5 'UTR region of the IFITM5 gene to be the most accurate approach to meet the needs of this study. Genomic DNA extraction was performed from the ethylenediaminetetraacetic acid (EDTA)-preserved blood samples using the Gentra Puregene Blood Kit (QIAGEN, Germany) according to the manufacturer's protocol and stored at $-80^{\circ} \mathrm{C}$.

DNA samples were amplified using a PCR with a specially designed primer pair covering the $5^{\prime}$ UTR region and exon 1 of the IFITM5 gene.

The PCR reaction was performed with 5x HOT FIRE$\mathrm{Pol}^{\circ}$ Blend Master Mix Ready to Load (Solis BioDyne, Estonia). PCR reaction was performed with a Thermal Cycler (Applied Biosystems, USA) PCR machine. Additional details on the PCR procedures are available from the authors upon reasonable request.

Amplified PCR products were electrophoresed through a $1.5 \%$ agarose gel. PCR products were purified with Exonuclease I and Shrimp Alkaline Phosphatase (Thermo Fisher Scientific, USA). Sanger sequencing reactions were performed from purified PCR fragments using BigDye ${ }^{\bullet}$ Terminator v3.1 Cycle Sequencing Kit (Applied Biosystems, USA). Reactions were processed on the ABI3730xl instrument.

Sequence reads were analyzed with Sequence Scanner v1.0 of Applied Biosystems and aligned to the RefSeq sequence NM_001025295.1. Sequence analysis and pathogenic variant identification was performed with Mutation Surveyor DNA variant analysis software (Softgenetics, USA). Presence of a c.-14C $>$ T variant was controlled in a screened cohort. Predictions for the pathogenicity and functional impact of the 5'UTR variants were provided with Mutation Taster. All analyses were conducted at the University of Tartu (Estonia). Sequencing data is available from the authors upon reasonable request.

\section{Results}

\section{Results of mutational analysis}

According to clinical diagnosis, out of the 90 unrelated OI patients screened, OI was suspected only in one case (1.11\%). However, after screening of the 90 unrelated patients, we have identified four patients (4.44\%) harboring a heterozygous c. $-14 \mathrm{C}>\mathrm{T}$ variant in the $5^{\prime} \mathrm{UTR}$ region of the IFITM5 gene. Three patients came from the Ukrainian OI cohort. One patient came from Vietnamese cohort. There were no patients with OI type V among the Estonian OI population. Parents of three affected patients did not harbor pathogenic variants, which confirmed the de novo nature of the pathogenic variant. Only one patient had a family history of OI, whose mother was a carrier of a c. $-14 \mathrm{C}>\mathrm{T}$ heterozygous variant in the IFITM5 gene also. The overall prevalence of OI type V in the UT OI biobank was 5/337 (1.48\%) (Table 1).

HPC and radial head dislocation was identified in 4/5 patients. Interosseous membrane calcification and metaphyseal radiodense bands were observed in 3/5 cases. Three patients had bluish and two had grayish eye sclera. There were no registered cases of DI among our patients. However, patient 1 developed teeth brittleness of an unknown nature. Patient 1 had also developed hearing loss, which started at the age of 14 . Both patients 2 and 3 , which came from family with a history of OI, had joint laxity. The overall number of fractures in patients 1-5 ranged from 0.5 to 2.3 per year. Patients developed mostly mild deformity of their long bones in both their upper and lower extremities. Scoliosis and chest deformity was found in 3/5 patients. Only one patient was immobile. According to their height $\mathrm{Z}$ scores, the patients are shorter than average in the age and sex-matched group. Growth retardation seemed to be greater with age (Table 1). Detailed descriptions of the patients' cases are represented below.

\section{Patient 1}

Patient 1 is a 15 -year-old male (lock time September 2017) and the only child of a healthy non-consanguineous Ukrainian family (family 1) (Fig. 1b). His mother had her first pregnancy without a history of miscarriages. The pregnancy was full term without any health concerns. The patient's birth weight was $3.5 \mathrm{~kg}$ ( $\mathrm{Z}$ score $-0.06,48 \%$ centile), his birth length was $52 \mathrm{~cm}$ ( $\mathrm{Z}$ score $0.76,78 \%$ centile), and he was in good condition immediately after birth. The patient's current weight is $45 \mathrm{~kg}$ ( $\mathrm{Z}$ score $-1.32,9 \%$ centile) with a height of $135 \mathrm{~cm}$ ( $Z$ score $-3.93,0 \%$ centile). The patient has grayish eye sclera, brittleness of teeth, and hearing loss, which started at the age of 14 . The patient suffers from headaches, urolithiasis, and pyelonephritis.

The total number of fractures was eight. Patient 1 suffered his first fracture at the age of 1 year and 3 months in the right hip. The next fracture happened in the jaw, at the age of four, due to a fall. At the age of seven, the patient fractured his lower left leg. At the age of eight, the patient re-fractured their lower left leg along with fracturing their left arm. At the age of nine, the patient had received a blow to their hip, and within a month the patient had developed an irregular-shaped crack of the cortex where the blow had been dealt. The patient had equal thickening of the cortex on both side femurs. Within 2months, a sarcoma-like ossification was discovered, sized $5 \times 4 \mathrm{~cm}$, without a clear contour line. After 1.5 months, the ossification enlarged to $7 \times 5 \mathrm{~cm}$ with some thickening and a clearer contour line. In 2017, hyperplastic callus formation was extreme (Fig. 1c). The lower limb developed inflammatory symptoms: redness, fever, and enlarged in 
Table 1 Phenotype characteristics of $O$ l type $V$ patients

\begin{tabular}{|c|c|c|c|c|c|}
\hline & Patient 1 & Patient 2 & Patient 3 & Patient 4 & Patient 5 \\
\hline Age & 15 & 4 & 34 & 7 & 5 \\
\hline Sex & m & m & f & f & f \\
\hline Country & Ukraine & Ukraine & Ukraine & Ukraine & Vietnam \\
\hline Phenotype & Severe & Mild & Moderate & Moderate & Mild \\
\hline Mimicking classic Ol type & V & 1 & IV & IV & । \\
\hline Ol history in the family & No & Yes & Yes & No & No \\
\hline Hyperplastic callus & Yes, extreme & Yes & Yes & No & Yes \\
\hline Interosseous membrane calcification & Yes & Yes & Yes (fibula-tibia) & No & No \\
\hline Radial head dislocation & Yes & Yes & Yes & No & Yes \\
\hline Metaphyseal radiodense band & NA & Yes & Yes & No & Yes \\
\hline Hearing loss & Yes, age 14 & No & No & No & No \\
\hline Dentinogenesis imperfecta & No, teeth brittle & No & No & No & \\
\hline Sclera hue & Grayish & Bluish & Bluish & Grayish & Bluish \\
\hline Number of fractures & 8 & 4 & 26 & 16 & 5 \\
\hline Number of fractures per year & 0.5 & 1 & 0.8 & 2.3 & 1 \\
\hline Time of the first fracture & 1.3 & 7 months & at birth & 3 months & 2 \\
\hline First fractured bone & Femur & Left femur & Elbow, femur & Scapula & Lower leg \\
\hline The most frequently fractured bone & Femur & Femur & Femur & Legs & Lower leg \\
\hline Pyramidal/bell-shaped chest & Yes, severe & No & Yes & Yes & No \\
\hline Scoliosis & Yes & No & Yes & Yes & No \\
\hline Upper limb long bone deformity & Yes, mild & Yes, mild & Yes & No & Yes, mild \\
\hline Lower limb long bone deformity & Yes & Yes, mild & Yes & Yes, mild & Yes, mild \\
\hline Mobility & Immobile, lying & Walking & Walking (did not walk at age 9-14) & Walking & Walking \\
\hline Height (Z score) & -3.93 & 0.66 & -2.70 & -2.83 & -1.22 \\
\hline Birthweight and length & $52 / 3450$ & $51 / 2500$ & $52 / 3300$ & $50 / 2800$ & NA/2800 \\
\hline Joint laxity & No & Yes & Yes & No & NA \\
\hline
\end{tabular}

size (Fig. 1a). Patient 1 was diagnosed with pseudo osteosarcoma. Patient 1 underwent osteosynthesis. After a few months, the patient suffered a right hip fracture and underwent osteosynthesis of his right femur.

The patient developed deformation of the spine and combined deformities of his lower, upper limbs, and chest. The patient has HPC of the right humerus and both femurs (Fig. 1c), congenital synostosis of the right forearm (radioulnar interosseous membrane calcification), and contracture of his right elbow joint (radial head dislocation) (Fig. 1c). The patient suffers from severe HPC formation in the hips (from 2011, age 9). Due to severe callus, the patient is immobile and unable to sit (Fig. 1c). The bone mineral density (BMD) Z-score of the spine was -5.9 and the lower arm received a Z-score BMD of - 3.6. The patient underwent bisphosphonate treatment with pamidronate.

Results of histological bone biopsy analysis showed that his callus bone tissue is immature and hypercellular. The patient's new grown bone trabeculae have a high number of osteoblasts located at the basophil intercellular matter, with the inclusion of cartilage regions. Both the patient's osteoblasts and osteocytes do not show any abnormalities. On the contour line, there is quite a significant number of osteoclasts. The intertrabecular space is filled with numerous blood vessels and fibroreticular tissue. The blood vessels are sinusoidal with large wide pores. The patient's bone marrow is hypocellular and hydropic with regions with hemorrhagic infiltration.

\section{Patient 2}

Patient 2 is a 4-year-old boy (lock time May 2016) from a Ukrainian family with three generations of OI history from the mother's line (family 2) (Fig. 2a). The mother had a healthy full-term pregnancy, without any previous miscarriages. His birthweight was $2.5 \mathrm{~kg}$ ( $\mathrm{Z}$ score -1.68 , $5 \%$ centile), and his birth length was $51 \mathrm{~cm}$ (Z score 0.38 , $65 \%$ centile). There were no signs of deformities or fractures after delivery.

The patient's first fracture appeared at the age of 7 months in the femur during massage. At 8 and 11 months, the 


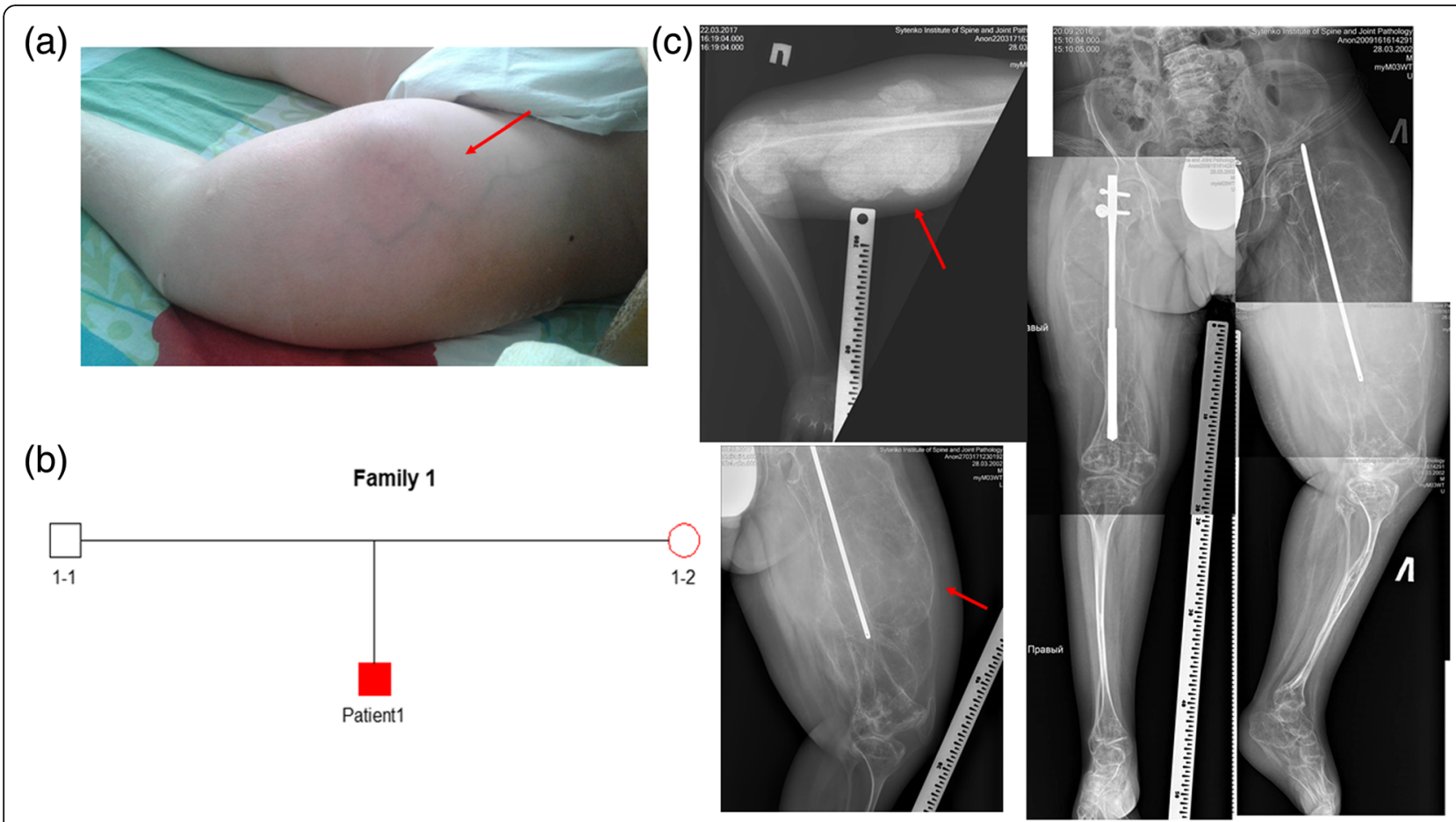

Fig. 1 Patient 1. a Hyperplastic callus formation in the femur. $\mathbf{b}$ Genealogical tree of patient 1 (family 1). c Radiological features of patient 1

(a)

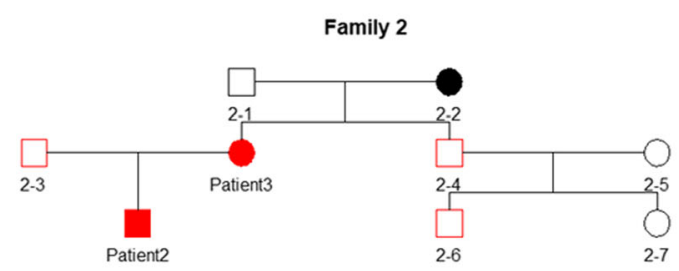

(b)
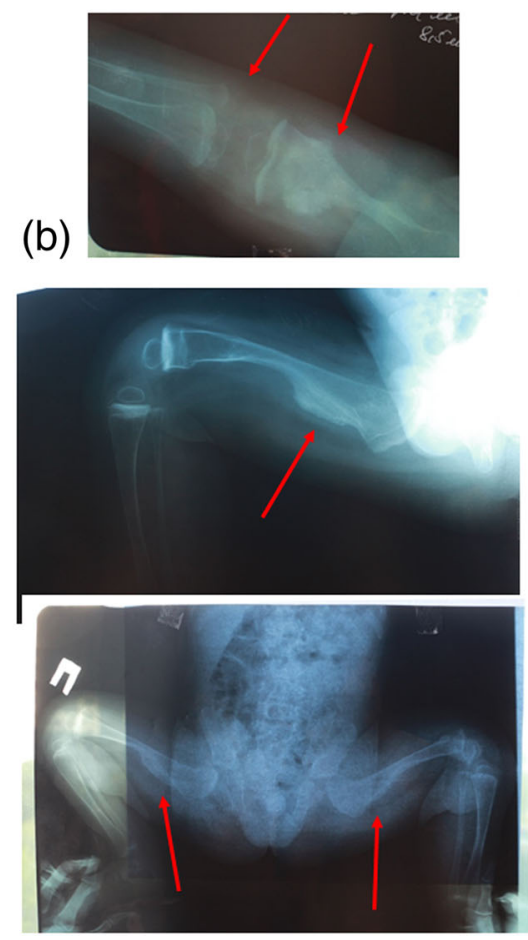
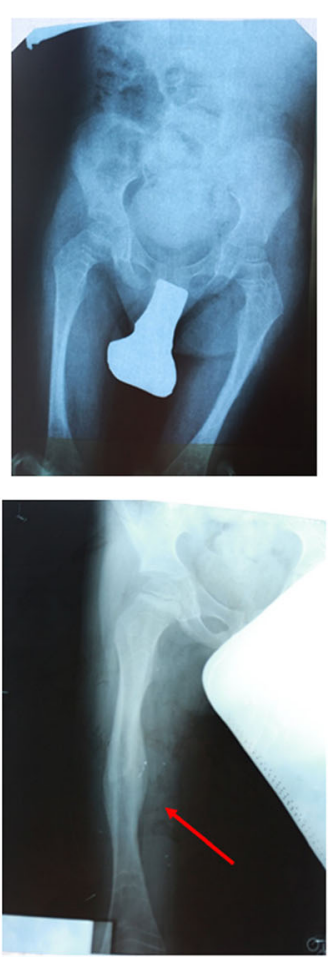

Fig. 2 Patient 2. a Genealogical tree of patients 2 and 3 (family 2). b Radiological features of patient 2 
patient fractured both their right and left femur. Afterwards, the patient followed treatment with pamidronate. The last fracture happened at the age of 4 , in the left forearm. The total number of fractures was 4 .

The patient's current weight is $15 \mathrm{~kg}$ ( $\mathrm{Z}$ score -0.68 , $25 \%$ centile) and their height is $105 \mathrm{~cm}$ ( $Z$ score 0.66 , $74 \%$ centile). The patient has bluish eye sclera and joint laxity. $\mathrm{He}$ is active and able to move independently. Signs of DI and hearing loss are absent.

Patient 2 has mild phenotype, mild deformities of chest, long lower and upper limb bones, with radial head dislocation and radioulnar interosseous membrane calcification (Fig. 2c). Investigation of X-rays showed the presence of HPC and a metaphyseal radiodense band (Fig. 2c).

\section{Patient 3}

Patient 3 is a 34-year-old female from Ukraine (lock time May 2016) and the mother of patient 2 (family 2) (Fig. 2a). Her birthweight was $3.3 \mathrm{~kg}$ ( $\mathrm{Z}$ score $-0.2,42 \%$ centile), and her birth length was $52 \mathrm{~cm}$ ( $Z$ score 1.0, 85\% centile). During being born, she had numerous fractures: both elbow, left hip, and both lower legs. The total number of fractures was 26 . The majority of the fractures affected the lower limbs, especially the femur. She became immobile between the ages of 9 and 14 .

At the age of 9, the lower and upper limbs developed HPC. She also has calcification of the interosseous membrane in the fibula and tibia along with radial head dislocation. An investigation of X-rays revealed the presence of a metaphyseal radiodense band. The patient had chest deformation, scoliosis, and deformities of the long bones in both upper and lower limbs (Fig. 3a). The patient currently walks independently. The patient has moderate phenotype, mimicking OI type IV, no DI, or hearing loss. Her eye sclera is bluish. The patient has joint laxity. Her current weight is $42 \mathrm{~kg}$ and her height is $145 \mathrm{~cm}$ (Z score $-2.70,0 \%$ centile).

\section{Patient 4}

Patient 4 is a 7-year-old girl from Ukraine (lock time May 2016). The patient has moderate OI phenotype, mimicking OI type IV without any visible features of OI type V. The patient was initially misdiagnosed with OI type IV. Patient 4 has no family history of OI (family 3) (Fig. 4a). Her birthweight was $2.8 \mathrm{~kg}$ ( $\mathrm{Z}$ score $-1.18,12 \%$ centile), and her birth length was $50 \mathrm{~cm}$ ( $\mathrm{Z}$ score $0.28,61 \%$ centile). There were no deformities or fractures during delivery;

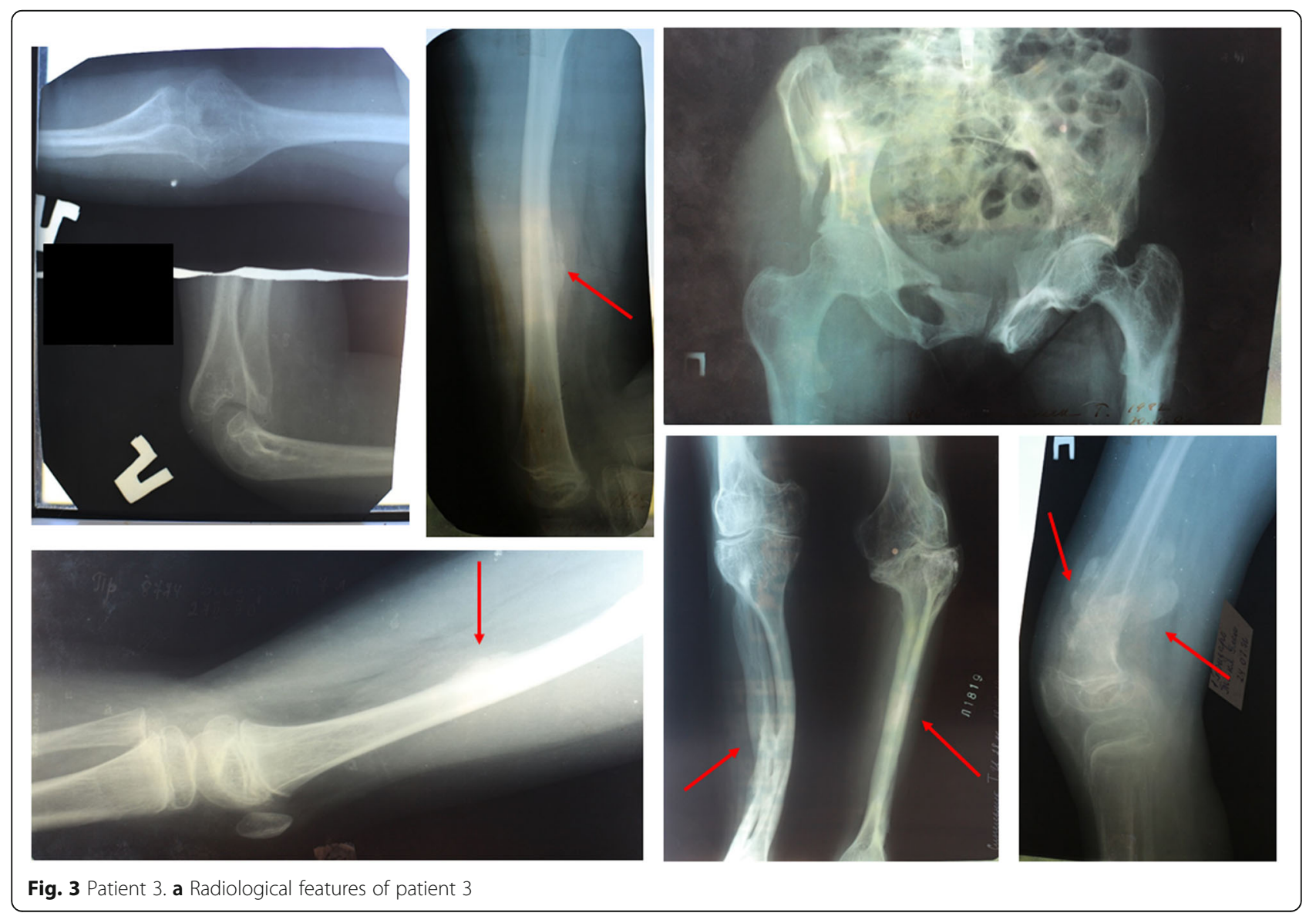


(a)

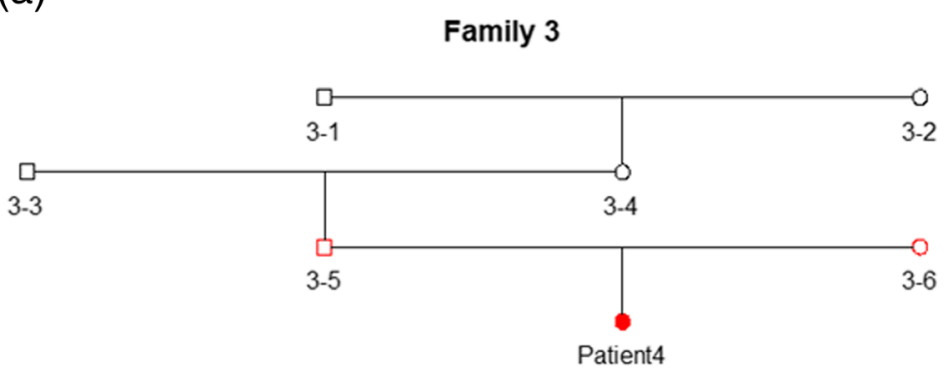

(b)
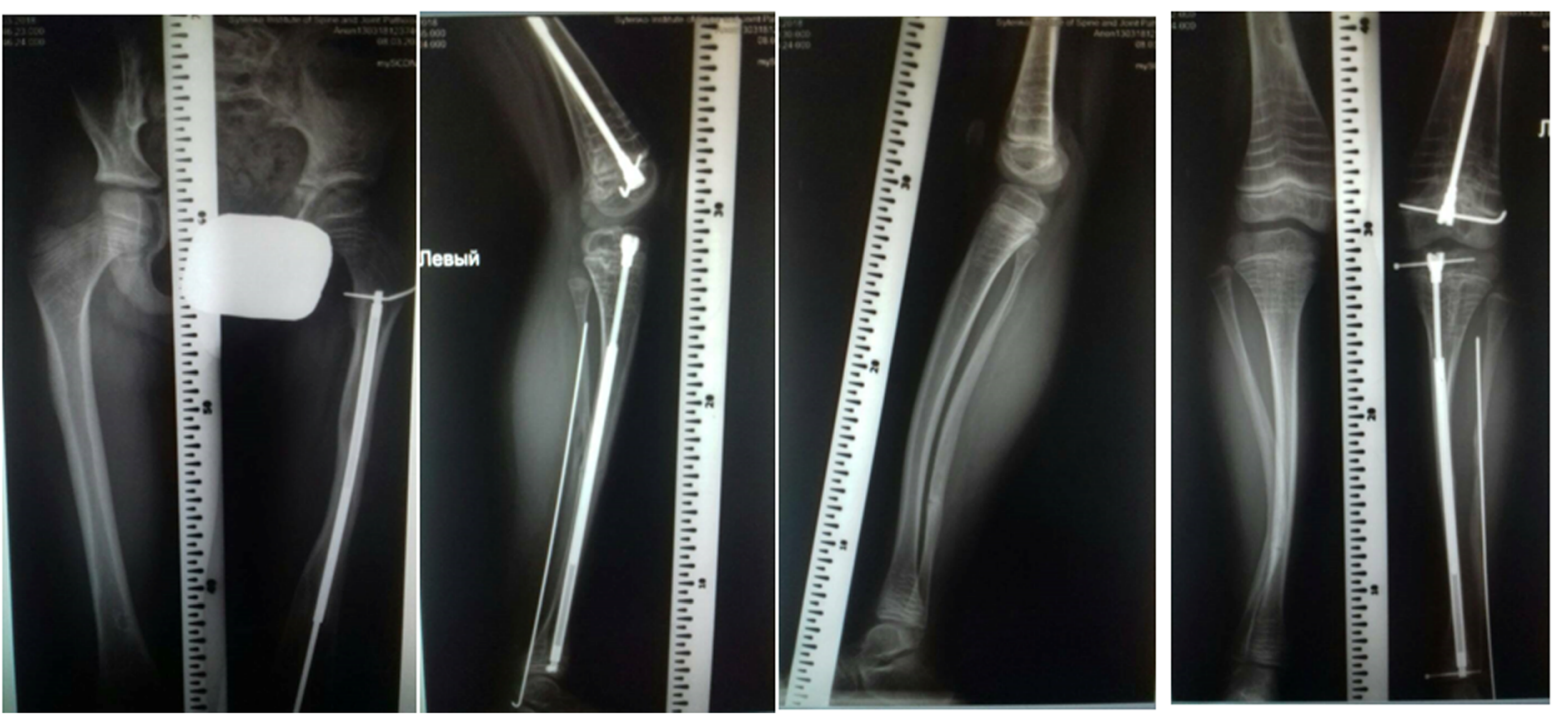

Fig. 4 Patient 4. a Genealogical tree of patient 4 (family 3). b Radiological features of patient 4

however, she had an unmineralized skull. At the age of 3 months, the first fracture appeared in the scapula during massage. The total number of fractures is 16 . Most fractures affected the lower limbs. The patient's left lower leg was fractured ten times. She had osteosynthesis on left lower and upper leg (Fig. 4b). The patient follows treatment with pamidronate. She has some deformities of lower limbs, spine, and chest (Fig. 4b). The patient had no hearing loss, DI, or joint laxity. Her eye sclera are gray. Her current weight is $17 \mathrm{~kg}$ ( $\mathrm{Z}$ score $-2.22,1 \%$ centile) and her height is $107 \mathrm{~cm}$ ( $\mathrm{Z}$ score $-2.83,0 \%$ centile). The patient is active and able to walk independently. Typical characteristics of OI type V, like HPC, interosseous membrane calcification, radial head dislocation, and a metaphyseal radiodense band, are absent.

\section{Patient 5}

Patient 5 is a 7-year-old girl from Vietnam, with mild OI phenotype (lock time 2015). Her father suffered some fractures in his forearms when he was under 10 years old. We do not have additional evidence of fractures in any of the other family members (family 4). An absence of consanguineous marriage was also confirmed (Fig. 5a). The mother had full-term pregnancy with 40 weeks of gestation, good health, and no history of miscarriages. Her birthweight was $2.8 \mathrm{~kg}$ ( $\mathrm{Z}$ score $-1.18,12 \%$ centile). Current clinical examination showed a weight $19 \mathrm{~kg}$ (Z score $-1.27,10 \%$ centile) and height $115 \mathrm{~cm}$ ( $Z$ score $1.22,11 \%$ centile). She has blue sclera.

The patient suffered her first fracture at the age of 2 years old. The patient had five fractures on both side tibias. Mild deformities appeared in the long bones of the forearms and lower legs (Fig. 5b). She is able to move normally. The patient did not follow bisphosphonate treatment. On the radiological examination, ossifications of the interosseous membrane between the ulna and radius and congenital dislocation of the radial head were present (Fig. 5b).

\section{Discussion}

Previous reports show that the proportion of OI type V patients may vary from 5 to $10 \%[10,39]$. According to our results, out of 337 OI patients in the UT OI biobank, less than $2 \%$ suffered from OI type V (five individuals). Interestingly, in a cohort of Palestinian OI patients, there were no carriers of the IFITM5 pathogenic variants, as well as among our Estonian OI population [40]. We do 


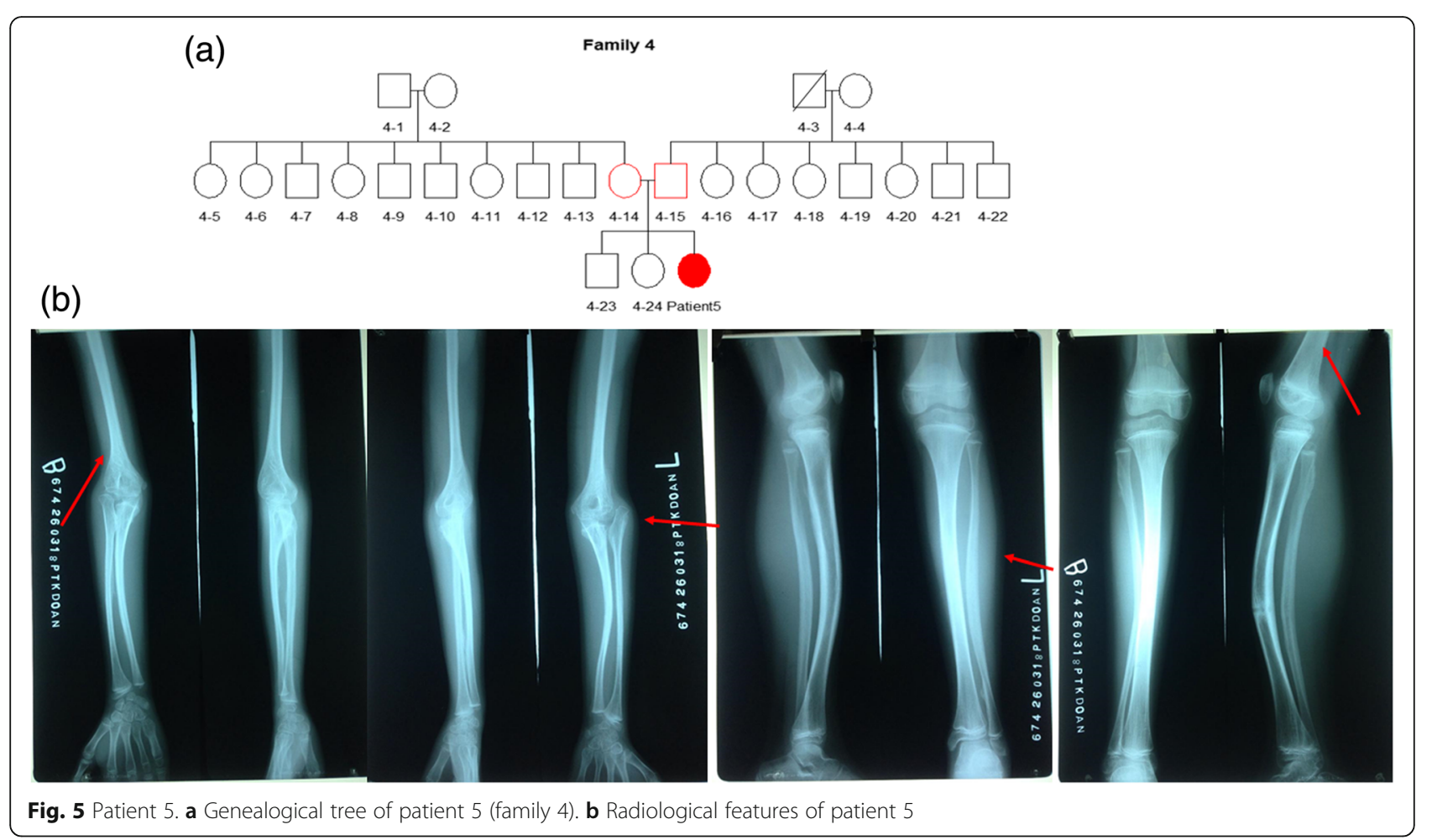

not have evidence to assume, that such differences might come from distinctions in the population genetics of different ethnic groups. But rather, the difference may be due to differences in population size and recruitment of patients. We were also surprised to find a relatively higher number of type $\mathrm{V}$ patients among Ukrainian OI cohort as compared to our Vietnamese OI population, as sample sizes and methods of patient recruitment were comparable.

Both the de novo and familial nature of the IFITM5 pathogenic variant was observed among our patients. In relation to previously published data, we could assume that the peak of the disease severity passes after puberty, and it does not affect reproduction in OI type $\mathrm{V}$ patients $[25,28$, 41]. However, similarly to collagen-related OI, the majority of cases appear due to de novo pathogenic variants [42].

Both de novo and familial cases of type $V$ showed a history of callus formation. As previous works have shown, the majority of patients had HPC [42]. Because of this, some patients may suffer from a series of misdiagnoses, which precede a proper diagnosis. For example, patient 1 from our current study was previously diagnosed with pseudo osteosarcoma due to extremely large HPC. Histological analysis has shown the presence of a mesh-like lamellation pattern typical for HPC in OI V [25]. The HPC in patient 1 represents the typical sign of OI V HPC, like primitive woven bone with inflammation, hypercellular trabeculae, and small cartilaginous islands [26].

Intriguing results were provided by study of Liu et al., which has shown that the typical OI type $\mathrm{V}$ pathogenic variant c.-14C $>\mathrm{T}$ in the IFITM5 gene promoted apoptosis in osteosarcoma cells, inhibited tumor invasion, and promoted osteogenic differentiation [43]. However, the exact mechanism is not yet known, interconnections of osteosarcoma and OI type $\mathrm{V}$ in the form of a MALEP-IFITM5 look encouraging for the management of both diseases. Thus, patients with extreme cases of HPC might be of interest.

Calcification of interosseous membrane was previously detected in all OI type $\mathrm{V}$ patients older than age 4 [25, 44]. Similarly, to described Chinese OI patients, we do not have any evidence of interosseous membrane calcification in patient 4 and 5 , who are 7 and 5 years old, respectively.

In addition to patterns of unusual mineralization, our patients suffered from ordinary OI symptoms, like bone fragility, recurrent fractures, skeletal deformations, hearing loss, joint laxity, teeth abnormalities, and bluish and grayish colored sclera. To our knowledge, hearing loss was identified in only one patient with OI type V [30]. Whereas, teeth abnormalities seemed to be more common. In the study of Kim et al., teeth abnormalities relevant to OI type V phenotype were identified in $11 / 16$ patients [45].

All of these characteristics might be caused by the altered effect of mutated MALEP-IFITM5 protein on collagen type I, as decreases in collagen expression were previously identified in OI type $\mathrm{V}$ primary osteoblast cultures and transgenic mouse models of OI type $\mathrm{V}$ [35, 46]. Thus, type I and IV mimicking symptoms might be 
connected to the presence of a quantitative collagen defect in patients with OI type V. Whereas, the formation of enormous bone callus and interosseous membrane calcification might be caused by the effect of mutated MALEPIFITM 5 on the process of increased mineralization in the bone tissue.

Genetic testing ruled out misdiagnoses and confirmed OI type $\mathrm{V}$ in patient 1 . It helped to build up an appropriate strategy for pharmacological and surgical treatment. Similarly, in the rest of revealed cases (patients 2-5), where classical OI was suspected, and treatment strategy was updated. More cautious treatment approach is needed to exclude risks and reduce potential complications, proceeding from the molecular defect of OI type $\mathrm{V}$. Moreover, results can be further used to provide family planning counseling for these families and support cost-effective and rapid genetic diagnosis of affected family members in following generations.

Phenotype severity varied between patients in both OI type $\mathrm{V}$ symptoms and classical OI features. The number of fractures was different. As well as in other OI types, the occurrence of fractures seemed to decrease after puberty. However, growth retardation increased with age and seemed to correlate with phenotype severity. The phenotypical variation of OI type $\mathrm{V}$ has led us to the conclusion that despite the OI causing effect, the presence of a pathogenic variant in the IFITM5 gene does not shape phenotype in its full guise. Additional modifying factors are not less important than the presence of the IFITM5 pathogenic variant itself and are yet to be discovered. A deep phenotyping description of OI type $\mathrm{V}$ patients with different phenotype severity and the collection of their genetic material is required for the further investigation and understanding of OI type V.

\section{Conclusions}

We have investigated the presence of the OI type $\mathrm{V}$ c.$14 \mathrm{C}>\mathrm{T} 5$ 'UTR IFITM5 pathogenic variant in a cohort of OI patients negative for collagen I pathogenic variants with and without symptoms of OI type V. We have identified five individuals with OI type V from Ukrainian and Vietnamese origin with various phenotype severity. Patient 4 had no visible features of OI type $V$, whereas patient 1 had an extreme case of hyperplastic callus formation. Data from our patients supports the presence of classical OI features (hearing loss, bluish and grayish sclera, joint laxity, teeth abnormalities) in OI type $\mathrm{V}$ in addition to typical OI type $\mathrm{V}$ features such as abnormal mineralization. Due to high variation in clinical symptoms, we suggest the testing of IFITM5 gene pathogenic variants in patients who lack OI type $\mathrm{V}$ features. Identifying what pathogenic variants cause OI is important for both doctors and patients, as it supports the organization of a proper treatment plan and follow ups for patient and helps for responsible family planning. Further investigations into the additional phenotype modifying factors and influence of MALEP-IFITM5 on osteogenesis should shed light on this rare and mysterious OI type.

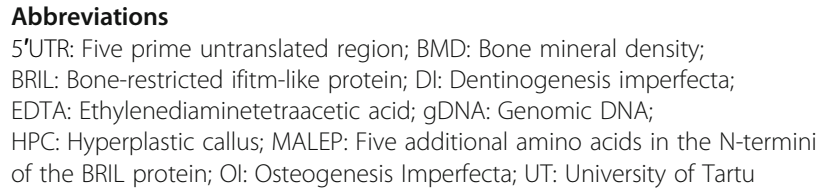

\section{Acknowledgements}

We would like to thank all of the patients and their relatives who participated in the study. Additionally, we extend our appreciation to the following people and organizations for their help and support with data collection: The Ukrainian Association of Crystal People; the Ol club in Vietnam; the workers of the Department of Traumatology and Orthopedics and Department of Pathophysiology; The University of Tartu; Hue University of Medicine and Pharmacy; Ardo Birk and Madis Karu for developing the online OI database of the Clinic of Traumatology and Orthopedics, TU Hospital.

\section{Authors' contributions}

LZ carried out the genetic studies, interacted with the patients, performed the data analysis, participated in the design of the study, and drafted the manuscript. KM participated in the design of the study, interacted with the patients, coordinated the blood sample collection, performed the data analysis, and helped to draft the manuscript. BHD participated in blood sample collection, interacted with the patients, and performed the data analysis. AP and SKh interacted with the patients and participated in design of the study and sample collection. EP, SKo, and ER carried out the genetic studies, performed the data analysis, and helped to draft the manuscript. AM participated in the designing of the study, coordinated the data interpretation and statistical analysis, and helped to draft the manuscript. All authors read and approved the final manuscript.

\section{Funding}

This work was supported by institutional research grant IUT20-46 of the Estonian Ministry of Education and Research by the projects DIOXMED and EVMED. Support was also received from the Estonian Ministry of Education and Research and by the H2020 ERA-chair grant (agreement 668989, project Transgeno).

\section{Availability of data and materials}

The datasets used and/or analyzed during the current study are available from the corresponding author upon reasonable request.

\section{Ethics approval and consent to participate}

The study was conducted in accordance with the Helsinki Declaration and authorized by the Ethical Review Committee on Human Research of the University of Tartu (Permit no. 221/M-34), the Ethical Review Board of Hue University Hospital (approval No. 75/CN-BVYD), and the Sytenko Institute of Spine and Joint Pathology of the Ukrainian Academy of Medical Sciences.

\section{Consent for publication}

Informed written consent was collected from all subjects and controls, or their legal representatives, prior to their participation in the study.

\section{Competing interests}

The authors declare that they have no competing interests.

\section{Author details}

${ }^{1}$ Department of Traumatology and Orthopeadics, University of Tartu, Puusepa 8, 51014 Tartu, Estonia. ${ }^{2}$ Clinic of Traumatology and Orthopeadics, Tartu University Hospital, Puusepa 8, 51014 Tartu, Estonia. ${ }^{3}$ Hue University of Medicine and Pharmacy, Hue University, Hue, Vietnam. ${ }^{4}$ Department of Pediatric Orthopedics, Sytenko Institute of Spine and Joint Pathology, AMS Ukraine, Pushkinska 80, Kharkiv 61024, Ukraine. ${ }^{5}$ Centre of Translational Medicine, University of Tartu, Ravila 14a, 50411 Tartu, Estonia. ${ }^{6}$ Department of 
Pathophysiology, University of Tartu, Ravila 19, 50411 Tartu, Estonia. ${ }^{\text {PPerron }}$ Institute for Neurological and Translational Science, QEll Medical Centre, Nedlands, WA, Australia.

Received: 17 December 2018 Accepted: 20 May 2019

Published online: 03 June 2019

\section{References}

1. Byers PH, Steiner RD. Osteogenesis imperfecta. Annu Rev Med. 1992; 43:269-82.

2. Van Dijk FS, Pals G, Van Rijn RR, Nikkels PGJ, Cobben JM. Classification of Osteogenesis Imperfecta revisited. Eur J Med Genet. 2010;53:1-5.

3. Rauch F, Glorieux F. Osteogenesis imperfecta. Lancet. 2004:363(9418):137785.

4. Sillence DO, Senn A, Danks DM. Genetic heterogeneity in osteogenesis imperfecta. J Med Genet. 1979;16:101-16.

5. Fratzl-Zelman N, Misof BM, Roschger P, Klaushofer K. Classification of osteogenesis imperfecta. Wien Med Wochenschr. 2015;165:264-70.

6. Van Dijk FS, Sillence DO. Osteogenesis imperfecta: clinical diagnosis, nomenclature and severity assessment. Am J Med Genet A. 2014;164A: 1470-81.

7. Marini JC, Forlino A, Bächinger HP, Bishop NJ, Byers PH, De PA, et al Osteogenesis imperfecta. Nat Rev Dis Primers. 2017;3:17052 Nature Publishing Group.

8. Shapiro JR. Clinical and genetic classification of osteogenesis imperfecta and epidemiology. In: Osteogenes. Imperfecta: A Translational Approach to Brittle Bone disease. Elsevier Inc (London, Waltham, San Diego); 2013. p. 1522.

9. Lange UC, Saitou M, Western PS, Barton SC, Surani MA. The fragilis interferon-inducible gene family of transmembrane proteins is associated with germ cell specification in mice. BMC Dev Biol. 2003;3:1.

10. Bardai G, Moffatt P, Glorieux FH, Rauch F. DNA sequence analysis in 598 individuals with a clinical diagnosis of osteogenesis imperfecta: diagnostic yield and mutation spectrum. Osteoporos Int. 2016;27:3607-13.

11. Osteogenesis Imperfecta Variant Database - Leiden Open Variation Database [Internet]. https://oi.gene.le.ac.uk/. Accessed 17 Dec 2018.

12. Baldridge D, Schwarze U, Morello R, Lennington J, Bertin TK, Pace JM, et al. CRTAP and LEPRE1 mutations in recessive osteogenesis imperfecta. Hum Mutat. 2008:29:1435-42.

13. van Dijk FS, Nesbitt IM, Zwikstra EH, Nikkels PGJ, Piersma SR, Fratantoni SA et al. PPIB mutations cause severe osteogenesis imperfecta. Am J Hum Genet. 2009;85:521-7.

14. Shaheen R, Al-Owain M, Sakati N, Alzayed ZS, Alkuraya FS. FKBP10 and Bruck syndrome: phenotypic heterogeneity or call for reclassification? Am J Hum Genet. 2010;87:306-7 author reply 308. Elsevier.

15. Valadares ER, Carneiro TB, Santos PM, Oliveira AC, Zabel B. What is new in genetics and osteogenesis imperfecta classification? J Pediatr. 2014;90:53641.

16. van Dijk FS, Zillikens MC, Micha D, Riessland M, Marcelis CLM, de DieSmulders CE, et al. PLS3 mutations in X-linked osteoporosis with fractures. N Engl J Med. 2013;369:1529-36.

17. Shaheen R, Alazami AM, Alshammari MJ, Faqeih E, Alhashmi N, Mousa $\mathrm{N}$, et al. Study of autosomal recessive osteogenesis imperfecta in Arabia reveals a novel locus defined by TMEM38B mutation. J Med Genet. 2012:49:630-5.

18. Garbes L, Kim K, Rieß A, Hoyer-Kuhn H, Beleggia F, Bevot A, et al. Mutations in SEC24D, encoding a component of the COPII machinery, cause a syndromic form of osteogenesis imperfecta. Am J Hum Genet. 2015;96:4329 The American Society of Human Genetics.

19. Symoens S, Malfait F, D'hondt S, Callewaert B, Dheedene A, Steyaert W, et al. Deficiency for the ER-stress transducer OASIS causes severe recessive osteogenesis imperfecta in humans. Orphanet J Rare Dis. 2013;8:154

20. Mendoza-Londono R, Fahiminiya S, Majewski J, Tétreault M, Nadaf J, Kannu $P$, et al. Recessive osteogenesis imperfecta caused by missense mutations in SPARC. Am J Hum Genet. 2015;96:979-85

21. Pyott SM, Tran TT, Leistritz DF, Pepin MG, Mendelsohn NJ, Temme RT, et al. WNT1 mutations in families affected by moderately severe and progressive recessive osteogenesis imperfecta. Am J Hum Genet The American Society of Human Genetics. 2013;92:590-7.

22. Becker I, Semler O, Gilissen C, Li Y, Bolz HJ, Giunta C, et al. Exome sequencing identifies truncating mutations in human SERPINF1 in autosomal-recessive osteogenesis imperfecta. Am J Hum Genet. 2011; 88:362-71.

23. Marini JC, Reich A, Smith SM. Osteogenesis imperfecta due to mutations in non-collagenous genes: lessons in the biology of bone formation. Curr Opin Pediatr. 2014;26:500-7.

24. Glorieux FH, Rauch F, Plotkin H, Ward L, Travers R, Roughley P, et al. Type V osteogenesis imperfecta: a new form of brittle bone disease. J Bone Miner Res [Internet] John Wiley and Sons and The American Society for Bone and Mineral Research (ASBMR). 2000;15:1650-8.

25. Rauch F, Moffatt $P$, Cheung M, Roughley P, Lalic L, Lund AM, et al. Osteogenesis imperfecta type $\mathrm{V}$ : marked phenotypic variability despite the presence of the IFITM5 c.-14C\&gt;T mutation in all patients. J Med Genet. 2013:50:21-4.

26. Cheung MS, Glorieux FH, Rauch F. Natural history of hyperplastic callus formation in osteogenesis imperfecta type V. J Bone Miner Res. 2007;22: 1181-6. A.

27. Balasubramanian M, Parker MJ, Dalton A, Giunta C, Lindert U, Peres LC, et al. Genotype-phenotype study in type $\mathrm{V}$ osteogenesis imperfecta. Clin Dysmorphol. 2013;22:93-101.

28. Fitzgerald J, Holden P, Wright H, Wilmot B, Hata A, Steiner RD, et al. Phenotypic variability in individuals with type $\vee$ osteogenesis imperfecta with identical ifitm5 mutations. J Rare Disord. 2013;1:37-42.

29. Guillén-Navarro E, Ballesta-Martínez MJ, Valencia M, Bueno AM, MartinezGlez V, López-González V, et al. Two mutations in IFITM5 causing distinct forms of osteogenesis imperfecta. Am J Med Genet A. 2014;164:1136-42.

30. Shapiro JR, Lietman C, Grover M, Lu JT, Nagamani SC, Dawson BC, et al. Phenotypic variability of osteogenesis imperfecta type $\mathrm{V}$ caused by an IFITM5 mutation. J Bone Miner Res [Internet] Wiley-Blackwell. 2013;28:1523-30.

31. Grover M, Campeau PM, Lietman CD, Lu JT, Gibbs RA, Schlesinger AE, et al. Osteogenesis imperfecta without features of type $V$ caused by a mutation in the IFITM 5 gene. J Bone Miner Res. 2013;28:2333-7.

32. Cho $T-J$, Lee $K-E$, Lee $S-K$, Song $S J$, Kim $K J$, Jeon $D$, et al. A single recurrent mutation in the 5'-UTR of IFITM5 causes osteogenesis imperfecta type $\mathrm{V}$. Am J Hum Genet. 2012;91:343-8.

33. Semler O, Garbes L, Keupp K, Swan D, Zimmermann K, Becker J, et al. A mutation in the $5^{\prime}$-UTR of IFITM5 creates an in-frame start codon and causes autosomal-dominant osteogenesis imperfecta type $V$ with hyperplastic callus. Am J Hum Genet. 2012;91:349-57.

34. Lazarus S, Mclnerney-Leo AM, McKenzie FA, Baynam G, Broley S, Cavan BV, et al. The IFITM5 mutation C.-14C \&gt; T results in an elongated transcript expressed in human bone; and causes varying phenotypic severity of osteogenesis imperfecta type V. BMC Musculoskelet Disord. 2014:15:107.

35. Lietman CD, Marom R, Munivez E, Bertin TK, Jiang M-M, Chen Y, et al. A transgenic mouse model of $\mathrm{Ol}$ type $\mathrm{V}$ supports a neomorphic mechanism of the IFITM5 mutation. J Bone Miner Res Wiley-Blackwell. 2015;30:489-98.

36. Zhytnik L, Maasalu K, Reimann E, Prans E, Köks S, Märtson A. Mutational analysis of COL1A1 and COL1A2 genes among Estonian osteogenesis imperfecta patients. Hum Genomics. 2017;11:19.

37. Ho Duy B, Zhytnik L, Maasalu K, Kändla I, Prans E, Reimann E, et al. Mutation analysis of the COL1A1 and COL1A2 genes in Vietnamese patients with osteogenesis imperfecta. Hum Genomics. 2016;10:27.

38. Binh HD, Maasalu K, Dung VC, Ngoc CTB, Hung TT, Nam TV, et al. The clinical features of osteogenesis imperfecta in Vietnam. Int Orthop. 2017:41:21-9.

39. Liu Y, Asan MD, Lv F, Xu X, Wang J, et al. Gene mutation spectrum and genotype-phenotype correlation in a cohort of Chinese osteogenesis imperfecta patients revealed by targeted next generation sequencing. Osteoporos Int. 2017;28:2985-95.

40. Essawi O, Symoens S, Fannana M, Darwish M, Farraj M, Willaert A, et al. Genetic analysis of osteogenesis imperfecta in the Palestinian population: molecular screening of 49 affected families. Mol Genet Genomic Med. 2018;6:15-26.

41. Zhang Z, Li M, He J-W, Fu W-Z, Zhang C-Q, Zhang Z-L. Phenotype and genotype analysis of Chinese patients with osteogenesis imperfecta type. PLoS One. 2013;8:e72337 V. Toft M, editor.

42. Hanagata N. IFITM5 mutations and osteogenesis imperfecta. J Bone Miner Metab. 2016;34:123-31.

43. Liu B-Y, Lu Y-Q, Han F, Wang Y, Mo X-K, Han J-X. Effects of the overexpression of IFITM5 and IFITM5 c.-14C\&gt;T mutation on human osteosarcoma cells. Oncol Lett. 2017;13:111-8. 
44. Shapiro JR, Lietman C, Grover M, Lu JT, Nagamani SC, Dawson BC, et al. Phenotypic variability of osteogenesis imperfecta type $\mathrm{V}$ caused by an IFITM 5 mutation. J Bone Miner Res. 2013;28:1523-30.

45. Kim O-H, Jin D-K, Kosaki K, Kim J-W, Cho SY, Yoo WJ, et al. Osteogenesis imperfecta type $\mathrm{V}$ : clinical and radiographic manifestations in mutation confirmed patients. Am J Med Genet A. 2013;161:1972-9.

46. Reich A, Bae AS, Barnes AM, Cabral WA, Hinek A, Stimec J, et al. Type V Ol primary osteoblasts display increased mineralization despite decreased COL1A1 expression. J Clin Endocrinol Metab. 2015;100:E325-32.

\section{Publisher's Note}

Springer Nature remains neutral with regard to jurisdictional claims in published maps and institutional affiliations.

Ready to submit your research? Choose BMC and benefit from:

- fast, convenient online submission

- thorough peer review by experienced researchers in your field

- rapid publication on acceptance

- support for research data, including large and complex data types

- gold Open Access which fosters wider collaboration and increased citations

- maximum visibility for your research: over $100 \mathrm{M}$ website views per year

At $\mathrm{BMC}$, research is always in progress.

Learn more biomedcentral.com/submissions 